\title{
The joys of summer
}

\section{A landmark for the Les Houches series of summer schools underlines the benefit of such activities to researchers of all ages.}

Conferences these days can feel more like pentathlon events: navigating overcrowded programmes, running between parallel sessions, finalizing your presentation minutes before you're due to speak, keeping up with e-mails during the talks, and making Skype calls during coffee breaks. By the end of the day you are likely to be exhausted, having probably forgotten most of the contributions and failed to talk to half of the people you wanted to. That is not to say that there is not still great benefit in attending scientific meetings - but how about taking some time off for a summer retreat?

Summer schools are excellent opportunities for physicists at any level of their career. For students, as well as a programme of topical lectures, the schools offer time to get to know people and start building your future professional network - your future boss, your future collaborators (and competitors). For more senior people, it's a good chance to catch up with colleagues, to spot new talent and to get new ideas. The best environment in which to achieve all this is somewhere far removed from the demands of everyday life, and ideally - although it's almost inconceivable these days - without internet access.

École de Physique des Houches is the oldest physics summer school in Europe, and is this month hosting its 100th meeting. It was founded in 1951 by the French physicist Cécile DeWitt-Morette, in the alpine village of Les Houches, overlooking the Mont Blanc massif. Over the years, the École des Houches has welcomed a large number of students and lecturers, the latter group including such famous names as Enrico Fermi, Wolfgang Pauli, Murray Gell-Mann, Pierre de Gennes, William Shockley, Georges Charpak, Hans Dehmelt and Philip Anderson.

Léon van Hove - a theoretical physicist, Director General of CERN from 1976 to 1980, and pictured here with Enrico Fermi - was the first to teach in Les Houches in the summer of 1951. For eight weeks, the students and lecturers lived almost like hermits, in alpine chalets with very little in the way of comfort and taking lectures outside when the weather permitted.

In a letter to DeWitt-Morette, Freeman Dyson wrote, "As I remember it, the school was an overwhelming experience. We were sharing every waking hour with a bunch of ebullient young people ... But the lectures were the least important part of the school. Much more memorable were the informal sessions, the meals and the walks, the daily hardships of mud and rain we all shared ... We all lived together in a cowshed and gave lectures in a barn ... living together under primitive conditions is a wonderful way to make friends. Bad weather makes friendships closer."

From its humble beginnings, the school has gone on to great success, renowned not only for its stunning location but also for the high quality of its meetings. Originally dedicated to theoretical physics, École de Physique des Houches now covers all areas of the discipline, as well as mathematics,

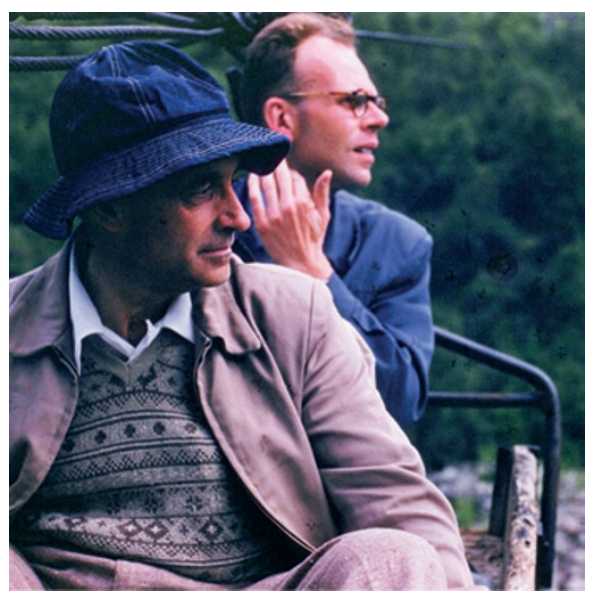

The great outdoors: Enrico Fermi (front) and Léon van Hove (back) heading up the Aiguille du Midi by chair lift, in the summer of 1954 (photograph courtesy of Roy Glauber).

chemistry, biology and Earth sciences. Besides the (now) two summer schools held annually in July and August, conferences and workshops are organized throughout the year. Today, the alpine chalets are cosy, the lecture theatre and study rooms well-fitted - and there is no longer any escape from e-mails, thanks to a broadband internet connection.

To talk, listen, discuss, network - these undoubtedly constitute the purpose of a scientific meeting. But the meetings are also to be enjoyed, so, wherever you go this summer, take the time to do so.

\section{Grand tour}

\section{A massive electromagnet is making a fantastic voyage from Brookhaven to Fermilab.}

Particle physics is renowned for its huge and expensive - experimental facilities. But a propensity to recycle equipment, whether large or small, is often overlooked. In one such example of frugality, an annullar electromagnet 50 feet in diameter is being transported from Brookhaven, on Long Island, New York, to be reused in a new experiment at Fermilab, outside Chicago, Illinois. The 3,200-mile trip for the 1990s-built kit comes at a price that is just one tenth of the cost of building it anew.

The electromagnet, made of aluminium and steel, contains superconducting coils that cannot withstand damage. Hence the ring is to make a slow voyage, first by truck to Smith Point Marina on Long Island; then by barge down the east coast and up the Mississippi, Illinois and Des Plaines rivers. Finally, it will arrive, through rolling roadblocks on the back of a purpose-built truck, at Fermilab in July.
The electromagnet will still serve its original purpose as a storage ring for muons, but in the next generation of experiment to probe the anomalous magnetic moment of the muon. (Using the precession of the moment in a magnetic field it's possible to test for the influence of predicted, or unknown, particles that might be spontaneously created from the vacuum.)

The progress of the ring can be followed on a map at http://muon-g-2.fnal.gov/bigmove $\square$ 